\title{
Extubation Failure After Successful Spontaneous Breathing Trial: Prediction Is Still a Challenge!
}

The timing of extubation is crucial during critical illness, since either delayed or premature discontinuation from mechanical ventilation is associated with an increased risk of morbidity and mortality, ${ }^{1}$ and the literature suggests that an early identification of patients who are able to breathe spontaneously reduces the duration of mechanical ventilation and complication rate. ${ }^{1}$ However, even when a spontaneous breathing trial (SBT), with either a T-piece or low-pressure support, has been successfully passed, failure of planned extubation occurs in approximately $15 \%$ of patients. ${ }^{2}$ Patients requiring reintubation have a high mortality rate and longer ICU stay, ${ }^{1,2}$ likely due to a worse severity of illness at extubation, or to clinical deterioration resulting from extubation failure, reintubation, and/or prolongation of mechanical ventilation.

The SBT predicts the patient's tolerance of unassisted breathing, but it does not challenge the patient on the ability to tolerate endotracheal tube removal. ${ }^{3}$ Factors associated with extubation failure include older age, ${ }^{2}$ worse severity of illness, ${ }^{2}$ pneumonia as the reason to initiate mechanical ventilation, ${ }^{4}$ inadequate cough, ${ }^{5}$ excessive respiratory secretions, ${ }^{6,7}$ upper-airway obstruction, ${ }^{3}$ and hypercapnia. ${ }^{8,9}$ The evidence is more controversial concerning the importance of neurological impairment, since some studies found it a risk factor, ${ }^{8}$ whereas others did not find an association between decreased level of consciousness and extubation failure. ${ }^{1,2}$ Another important and common risk factor is cardiac dysfunction, ${ }^{3}$ the prompt diagnosis of which allows effective treatment. Chien et al ${ }^{10}$ found that $\mathrm{a}<20 \%$ variation in plasma brain natriuretic peptide from the pre-SBT baseline improved the predictive value of the SBT for successful extubation from $80 \%$ to $97 \%$.

\section{See the Original Study on Page 178}

The study by Miu and co-workers ${ }^{11}$ in this issue of RESPIRATORY CARE adds to this information, with the specific aim of building a model able to predict extubation failure, either within the first 24 hours (early failure) or at any time, in a large population of critically ill adults who have passed a traditional SBT. Miu et al collected data from the medical records of 2,007 patients admitted to medical, cardiac, trauma/surgical, neurological/neurosurgical, and burn ICUs, who required invasive mechanical ventilation via endotracheal tube. Among all the patients analyzed, 379 (19\%) failed extubation at any time, and the most common reason was respiratory failure $(76 \%)$, followed by airway obstruction (17\%). Early reintubation occurred in $155(7.7 \%)$ patients. Unfortunately, data concerning noninvasive ventilation (an important resource in the management of post-extubation respiratory failure ${ }^{12}$ ) are not reported. In both the models that Miu et al studied, independent predictors associated with reintubation were a higher illness severity (as measured with the Simplified Acute Physiology Score II) at admission, higher amount of secretions, higher minute ventilation, higher number of failed SBTs, and lower oxygenation. Those data confirm the results of previous study, ${ }^{4,6,8,13}$ with the added value of generalizing them to a larger and more heterogeneous patient population. In line with the findings by Coplin et al, ${ }^{14}$ Miu et al found that neurologic function (as assessed with the Glasgow Coma Scale) seems not to be associated with extubation failure.

Furthermore, Miu et al took the additional step of creating 2 models for extubation failure: one for failure at any time, and another for failure in the first 24 hours. Despite some overlap, they found that the variables predicting early failure are not the same as those predicting failure at any time: oxygenation impairment was associated with early failure, whereas lower diastolic pressure and number of failed SBTs were associated with extubation failure at any time. The accuracy of the model in predicting extubation failure was, unfortunately, rather low: 70\%, in comparison with the 50\% accuracy of flipping a coin.

The identification of lower diastolic pressure as a risk factor for extubation failure has not been previously reported, and Miu et al do not provide a compelling explanation for this association. We cannot conclude whether low diastolic pressure is a contributing cause of extubation failure or if they simply coexist in the same patients. Miu et al refer to previous studies concerning the correlation between diastolic dysfunction and the ventilator-weaning process. Switching from continuous mandatory ventilation to supported spontaneous-breathing ventilation can unmask latent ventricular heart failure, because of the additional work imposed on the cardiovascular system, leading to pulmonary edema (if diastolic dysfunction) or to inadequate increase of cardiac output (if systolic dysfunction). 


\section{Extubation Failure After Successful Spontaneous Breathing Trial}

However while diastolic pressure is an important determinant of afterload, it is not equivalent to diastolic dysfunction. Diastolic dysfunction depends on a prolonged leftventricular relaxation and increased stiffness, which could lead to a higher left end ventricular pressure and high risk of pulmonary edema. ${ }^{15-17}$ Another potential mechanism is reduced coronary perfusion in the presence of low diastolic pressure. The evaluation of cardiac function via transthoracic echocardiography has been presented in recent studies, ${ }^{18,19}$ but data about diastolic pressure are new and, if confirmed, more easily obtainable.

In conclusion, although some of the presented findings are already reported in the literature, the large cohort studied is an undeniable strength of the study by Miu and co-workers. As with any novel scoring system, prospective validation is needed to understand its usefulness in clinical decision making. Moreover, a clear explanation of the mechanisms underlying the association between low diastolic pressure and extubation failure is needed, prompting novel investigations on cardiac-related extubation failure.

Salua Abd El Aziz El Sayed Deab MD
Giacomo Bellani MD PhD
Department of Health Sciences,
University of Milan-Bicocca
Monza, Italy
and
Emergency Department
San Gerardo Hospital
Monza, Italy

\section{REFERENCES}

1. Epstein SK, Ciubotaru RL, Wong JB. Effect of failed extubation on the outcome of mechanical ventilation. Chest 1997;112(1):186-92.

2. Thille AW, Harrois A, Schortgen F, Brun-Buisson C, Brochard L. Outcomes of extubation failure in medical intensive care unit patients. Crit Care Med 2011;39(12):2612-2618.

The authors have disclosed no conflicts of interest.

Correspondence: Salua Abd El Aziz El Sayed Deab MD, Department of Health Sciences, University of Milan-Bicocca, Via Pergolesi 33, Monza, Italy. E-mail: salua.deab@gmail.com.

DOI: $10.4187 /$ respcare.03037
3. Thille AW, Cortés-Puch I, Esteban A. Weaning from the ventilator and extubation in ICU. Curr Opin Crit Care 2013;19(1):57-64.

4. Frutos-Vivar F, Ferguson ND, Esteban A, Epstein SK, Arabi Y, Apezteguía $\mathrm{C}$, et al. Risk factors for extubation failure in patient following a successful spontaneous breathing trial. Chest 2006;130(6): 1664-1671.

5. Smina M, Salam A, Khamiees M, Gada P, Amoateng-Adjepong Y, Manthous CA. Cough peak flows and extubation outcomes. Chest 2003;124(1):262-268.

6. Salam A, Tilluckdharry L, Amoateng-Adjepong Y, Manthous CA. Neurologic status, cough secretions and extubation outcomes. Intensive Care Med 2004;30(7):1334-1339.

7. Khamiees M, Raju P, DeGirolamo A, Amoateng-Adjepong Y, Manthous CA. Predictors of extubation outcome in patients who have successfully completed a spontaneous breathing trial. Chest 2001; 120(4):1262-1270

8. Mokhlesi B, Tulaimat A, Gluckman TJ, Wang Y, Evans AT, Corbridge TC. Predicting extubation failure after successful completion of a spontaneous breathing trial. Respir Care 2007;52(12):1710-1717.

9. Sellarés J, Ferrer M, Cani E, Loureiro H, Valencia M, Torres A. Predictors of prolonged weaning and survival during weaning in a respiratory ICU. Intensive Care Med 2011;37(5):775-784.

10. Chien JY, Lin MS, Huang YC, Chien YF, Yu CJ, Yang PC. Changes in B-type natriuretic peptide improve weaning outcome predicted by spontaneous breathing trial. Crit Care Med 2008;36(5):1421-1426.

11. Miu T, Joffe AM, Yanez ND, Khandelwal N, Dagal AH, Deem S, Treggiari MM. Predictors of re-intubation in critically ill patients. Respir Care 2013;59(2):178-185.

12. Hess DR. The role of noninvasive ventilation in the ventilator discontinuation process. Respir Care 2012;57(10):1619-1625.

13. Sellarés J, Ferrer M, Torres A. Predictors of weaning after acute respiratory failure. Minerva Anestesiol 2012;78(9):1046-1053.

14. Coplin WM, Pierson DJ, Cooley KD, Newell DW, Rubenfeld GD. Implication of extubation delay in brain-injured patients meeting standard weaning criteria. Am J Respir Crit Care Med 2000;161(5): 1530-1536.

15. Zile MR, Brutsaert DL. New concepts in diastolic dysfunction and diastolic heart failure. Part I: diagnosis, prognosis and measurements of diastolic function. Circulation 2002;105(11):1387-1393.

16. Zile MR, Brutsaert DL. New concepts in diastolic dysfunction and diastolic heart failure: part II: causal mechanisms and treatment. Circulation 2002;105(12):1503-1508.

17. Vignon P. Ventricular diastolic abnormalities in the critically ill. Curr Opin Crit Care 2013;19(3):242-249.

18. Moschietto S, Doyen D, Grech L, Dellamonica J, Hyvernat H, Bernardin G. Transthoracic echocardiography with Doppler tissue imaging predicts weaning failure from mechanical ventilation: evolution of left ventricle relaxation rate during spontaneous breathing trial is the key factor in weaning outcome. Crit Care 2012;16(3):R81.

19. Caille V, Amiel JB, Charron C, Belliard G, Vieillard-Baron A, Vignon P. Echocardiography: a help in the weaning process. Crit Care 2010;14(3):R120 